\title{
Analysis of Power and Threat Manifestation in the Discourse of Traffic Police Officers: A CDA Perspective
}

\author{
Hossein Vahid Dastjerdi \\ English Department, the University of Isfahan, Isfahan, Iran \\ Email: h_vahid@yahoo.com \\ Mehdi Latifi \\ The University of Isfahan, Iran \\ Email: smm_latifi@yahoo.com \\ Elham Mohammadi \\ The University of Isfahan, Iran \\ Email: Elham.m@fgn.ui.ac.ir
}

\begin{abstract}
The present study was an attempt to capture the relationship between the role of social status and discourse in relation to choice of words and tone of the speakers. The way people put the words together and express it can sometimes be the source of coercion, threat and somehow extorting the others. In this article, the discourse of traffic police officers and drivers was precisely scrutinized in order to analyze the discriminatory or oppressive linguistic usage observable in exchanges among given social actors. In so doing, the study's focal point was on instances of illegitimate conversation exchanges between drivers plying highways and the traffic police officers who were controlling the drivers' speeding and traffic violations. A critical discourse analysis of such conversations, recorded through interview with the fined drivers, unveiled that illegitimate dealings are committed, and that whenever the monetary demand of officers is resisted, there are undesirable consequences for the drivers. In addition, the traffic police officers displayed their power in the language they used and, consequently, they were bribed on the sly by the drivers.
\end{abstract}

Index Terms — bribery, critical discourse analysis, oppressive linguistic usage, power

\section{INTRODUCTION}

In this article an effort is made to present a critical analysis of discourse exchanges between drivers and traffic police officers at traffic police stations on Isfahan-Tehran highway in Iran. The procedure taken for analysis is framed within the Critical Discourse Analysis (CDA) methodologies which are used to touch upon the exhibition of dominance, power and control in exchanges that make the traffic police officers the superior interlocutor. To this end, first of all, an introduction to CDA would be in order.

One of the rather new techniques of investigation used in qualitative research is critical discourse analysis. Foucault (1972) in his influential work on the ontology of knowledge, purported that a discourse includes not only written and spoken ideas and knowledge, but also attitudes, the way topics are addressed, the terms of reference used and the social practices embedded in conventions. Critical discourse analysis (CDA) expands textual discourse analysis by including conversations, interviews, observations, written materials and visuals. CDA is accordingly a mixture of linguistic and social theory that focuses on discourse within social practice. Historically, CDA was used to study everyday activities and social interactions within discrete settings including asylums, and prisons (Gubrium and Holstein, 2000). Current applications of CDA have turned out to include more settings. However, in 1970s there was the emergence of a type of discourse analysis which was later known as the role of language in forming power relations in society (Anthonissen, 2001). The approach was based on Halliday's (1994) Systemic Functional Linguistics (SFL). Critical Linguistics followers such as Trew (1979, p. 155) focused on "isolating ideology in discourse" and demonstrating "how ideology and ideological processes are manifested as systems of linguistic characteristics and processes." This end was pursued by developing CL's analytical tools (Fowler \& Hodge, 1979). Theoretically, this approach is characterized by a realist social ontology (which regards both abstract social structures and concrete social events as parts of social reality), a dialectical view of the relationship between structure and agency, and of the relationship between discourse and other elements or 'moments' of social practices and social events.

Followers of Critical Linguistics see the language in use as performing three functions together: ideational, interpersonal, and textual functions. According to Fowler (1991, p. 71), and H (1995, p. 25), whereas the ideational function refers to the experience of the speakers of the world and its phenomena, the interpersonal function embodies 
the insertion of speakers' own attitudes and evaluations about the phenomena in question, and establishing a relationship between speakers and listeners. During the course of time CL and what lately is more normally referred to as CDA (Chouliaraki \& Fairclough, 1999; van Dijk, 1998) has been further developed. Van Dijk (2001) considers 2 levels for CDA: Macro and Micro. He believes that the use of language, discourse, verbal interaction, and communication are classified in the micro level of the social order. However, power, dominance, and inequality between social groups are typically terms that entail the macro level of analysis. This means that CDA has to theoretically cover the well-known "gap" between micro and macro approaches, which is of course a distinction that is a sociological construct in its own right (Alexander, Giesen, Munch \& Smelser. 1987; Knorr-Cetina and Cicourel 1981). It can thus be claimed that the present study basically fits into the macro level.

Critical Discourse Analysis sees language as social practice (Fairclough \& Wodak 1997), and takes into account the context of language use to be of crucial importance (Wodak, 2000; Benke, 2000). Fairclough and Wodak (1997) state:

Critical Discourse Analysis sees discourse - language use in speech and writing - as a form of 'social practice'. Describing discourse as social practice implies a dialectical relationship between a particular happening and the situation or social structures which include it. That is, discourse is socially constitutive as well as socially conditioned it constitutes situations, objects of knowledge, and the social identities and relationships between people and groups of people. It is constitutive both in the sense that it helps to sustain and reproduce the social status quo, and in the sense that it contributes to changing it. Since discourse is so socially consequential, it gives rise to important issues of power. Discursive practices may have major ideological effects - that is, they can help, produce and reproduce unequal power relations between (for instance) social classes, and ethnic/ cultural majorities and minorities through the ways in which they represent things and position people (p. 258).

Such unequal power relations, they add, are manifested in many social encounters unavoidable in some professions (e.g. traffic police officers' job- the focus of the present study to touch upon).

According to Van Dijk (2001), a key concept in most critical studies on discourse is that of power, and more specifically the social power of groups or professions. In a nutshell, based on complex philosophical and social analysis, the social power is defined in terms of control. Thus, groups have power if they are able to control the acts and minds of the other groups. This ability assumes a power stand of advantaged access to limited social properties, such as force, money, status, fame, knowledge, information, "culture," or indeed various forms of public discourse and communication (see, e.g., Lukes 1986; Wrong 1979). Different types of power may be distinguished according to the various resources employed to use such power: the coercive power of the military (traffic police in the present study) will rather be based on force and threat and the rich will have power because of their money. But, it is worth mentioning that power is seldom absolute since it depends on situation and context, and this power can change from one place to another. Groups may more or less control other groups, or only control them in specific situations or social domains. Moreover, dominated groups may more or less resist, accept, comply with, or legitimate such power, and even find it "natural." The power of dominant groups may be integrated in laws, rules, norms, habits, and even a quite general consensus, and thus take the form of what Gramsci (1971) calls "hegemony". By means of this hegemony, some of the traffic police officers abuse their social status.

Hence, CDA is considered an apt tool for the purpose of the present study, as it reveals the subtle relationships that exist between social structures and discursive events (Fairclough and Wodak, 1997). CDA as a critical procedure is actually meant to investigate social inequalities which are illustrated in social interactions and are legitimized by language use (Wodak, 2001).

By CDA, the inter-relationships of social structures and discursive microstructures as defined by Van Dijk (1997) can be revealed by analyzing discriminatory or oppressive linguistic usage that is noticeable. CDA is also a means to unveil the implicit and explicit discrimination, oppression, and power-wielding manifest in written or spoken conversations (Dellinger, 1995). This issue is of major importance since it shows how social interactions influence people and their measures in the complex social encounter that eventually may end up in the creation of a discourses.

It can therefore be stated that the objective of CDA is, among other things, to reveal dominance relations between groups, expose the legitimating of power and the manufacture of consent (Kress, 1990).

The present study deals with a sociolinguistic phenomenon which is considered as an appalling problem with chief level of importance to the community. It is hoped that the following analysis and the findings thereof would persuade those in charge of certain jobs in society not to abuse their power any longer either in action or in talk.

\section{METHODOLOGY}

The data collection in this article was carried out during two months in three different traffic police stations on different highways. The conversations between the drivers and the police officer were transcribed immediately after the interview with the drivers. Since tape recording or a noticeable presence in the traffic police station office would endanger the true nature of the data, and the officers would not have their actual conversation in the presence of an observer (due to the fact that they were afraid of being reported), the fined or extorted drivers were interviewed shortly after leaving the police stations. Also, during the transcription task the drivers were asked to verbalize the motive behind articulating some of the sentences to let the researchers interpret the dialogues more accurately. 
In addition, some of the drivers were interviewed at their destinations which were rather close to the cities' traffic police stations, since a long presence in such areas could be given rise to suspicion of police officers and possible problems for the data collectors.

As for the traffic police officers, the data collectors travelled in their personal cars, pretending either a vehicle break down or stopping in order to take rest at different traffic police stations ( 5 in total) at various locations along highways (about $410 \mathrm{kms}$ ). Also, different data collectors were preferred because this would lead to randomness in the data collection procedure and prevent possible detection which might, among other things, affect the natural setting of the interview and the ease with which responses were obtained. In addition to the present articles' researchers, some of their colleagues were asked to participate as data collectors while they were traveling the target highways. This could add to the validity of the data collection procedure and reduce the risk of identification by the police officers.

\section{DATA ANALYSIS}

The existence of widespread traffic police stations on highways is fist because of the prevalent violation of speed limit on highways and second, due to the fact that some of the vehicles produced in some countries enjoy a low security level and hence in an accident may be severely damaged. Such police stations are set up close to each city. In addition some mobile police patrols lurk in some blind spots to fine the drivers who trespass the speed limit. Although traffic police officers' specific instructions are crystal clear to them, some officers usually go beyond these and perpetrate illegal deeds which will be discussed later on in the following section. The officers usually display and use a superior tone and diction in their discourse with drivers.

As for data analysis, after encountering and examining 50 different situations in total by the data collectors, the analysis revealed three main categories of conversational interaction, i.e. three major patterns of discourse exchange between the drivers and the traffic police officers were spotted after analyzing the entire transcriptions in all different situations. In the transcriptions many of the conversation wordings and styles were more or less repeated with similar patterns. However, there were three general patterns of systematic recurrence of certain expressions that point to the same issue of asking for bribe and the manifestation of power in the language used by the traffic police officers. Each distinguished pattern indentified in the data analysis will be discussed under different headings, to be elaborated on and discussed comprehensively. This would be more suitable for an ample microanalysis of the discourse exchanged between the two parties. The three categories can be explained under these headings: 1.) indirect techniques to request money, 2.) direct techniques to request money, and 3.) making some excuses to extort money of the drivers. Each of these is discussed below. It is to be noted that for the sake of brevity, just one sample of the collected data is presented for each category.

\section{A. Situation One: Indirect Techniques to Request Money}

In this section those propositions which were made by traffic officers to indirectly ask for money will be discussed. The drivers here were caught for violating the speed limit and were stopped by the traffic police officers to get a fine ticket for speeding. Extract A below shows one sample dialogue exchanged between the two parties. From now on the police officers are abbreviated as PO and the drivers are shown by D in all the extracts.

Extract A:

1. PO: pull over

2. D: (after stopping the car and going towards the officer). Good job officer, something wrong?

3. PO: You were over speeding (PO is frowning)

4. D: Are you sure? Oh no, please neglect it I am in such a hurry, if I get late there, I will miss something very important. Just this time, please.

5. PO: Your ticket would be about 20 \$, so what should we do?

6. D: Ok, please check my documents (money is included)

7. PO: Everything is fine, go.

Here, at first, the driver pretended that he knew nothing about the reason that he was stopped (2). By this he wanted to send an indirect message to the police officer showing that he was not aware of breaking the speed limit due to some distractions. This trick may have influenced the officer to feel pity for the driver. However, in (3) the police officer attributed blame to the driver for violating the speed limit. The accusation is grave in that it entails an illegal act to the driver and indirectly imposes the power of police officer over the driver. This immediately prompts the reaction of the driver as if he did not know it and it was only negligence. After that, in (4) the seemingly surprised driver tried to make some excuses to alleviate the punishment. The conversations included in this category usually contained excuses such as having someone waiting for drivers or losing a very important appointment. But, the traffic police officer disregarded the exchanges so far and in (5) he mentioned the amount of penalty for over speeding. In the next sentence, the PO made his point indirectly by raising a question and hesitating to see the reaction of the driver- what should we do? In (6) the driver got the point and secretly bribed the officer. To avoid the direct bribing the driver put the money in the documents. Usually, giving the document to the PO voluntarily is the sign of bribing in the conversations. Finally, in (7) the officer accepted the offered money by giving the documents back and letting the driver move on.

\section{B. Situation Two: Direct Techniques to Request Money}


Extract B:

1. PO: Park your car and take your documents to the office.

2. D: Ok sir, something wrong?

3. PO: You were reported for over speeding by our cameras.

4. D: There must be a mistake. I was driving with low speed. I have never exceeded the speed limit.

5. PO: Really? You were reported by your license plate. The documents are available inside the office. Your vehicle should be stopped here and your driver's license must be attached. Shake a leg, we are running out of time.

6. D: Please sir, I am really busy these days.

7. PO: None of my concern, but there might be another way to pay it in cash.

8. D: Sure, thank you.

In this situation, in (1), again after parking the car and the request to check the documents the driver pretended that he knows nothing about the reason that he was stopped (2). The PO accused the driver of over speeding but in (4) the driver evaded the officer's blame tactic by ignoring the accusation and countering it with a cordial and polite verbal move. The driver wanted to deny any charge against him. However, in (5) the PO insisted on over speeding issue and mentions to the availability of some documents to justify his word. In so doing, he used the word "really" to start his sentence that shows he is talking from a superior position and to make fun of the driver. Thereafter, he became even more aggressive and threatened the driver to stop his vehicle. In such conversations there are instances in which drivers make conversational moves to appease, for example, by using deferential expressions whenever there is a hint of threat from POs. In (6), it can be seen that the driver's resistance to plead not guilty was not successful and did not stop the extortion from being carried out. Hence, the driver tried to appease the tone of the PO by trying to show his desperation. Finally, in (7) the police officer directly made his point and asked for money with audacity. It seems that the additional threats to stop the car and attach the driver's license were an introduction to get the money. This was done without any apparent resistance on the part of the driver and thus, the PO got bribed by the driver. This direct technique to extort money is becoming more prevalent. Actually, in 20 (out of 50) of the situations the police officers asked for money in this manner.

\section{Situation Three: Extorting Money by Making Some Excuses}

This situation usually happens to the truck drivers.

Extract C:

1. PO: Park your car.

2. D: Ok, but is there a problem?

3. PO: Let me take a look at your documents and waybill to see what you are carrying...Ok, the documents are fine but I should check your truck load, it takes time, you should wait for a while.

4. D: Sir I should keep going. I am sure there is nothing wrong.

5. PO: But, I should do my duty. I told you it takes time. I think the truck is overloaded.

7. D: Here, please double check my documents. (Money is placed in the documents).

8. PO: Ok no problem. You can go. I don't like to keep you waiting.

In this situation, there is no over speeding accusation and the truck driver is asked to pull over for normal checking. However, in (3) the police officer started to send indirect signals to the driver that he is expecting money. After the approval of the documents by the PO, he started to make some excuses for still keeping the driver. But in (4) the driver's response was somehow different. Such cases are indicators of a kind of resistance by some drivers and an attempt to challenge the authority and power of the traffic officers. But, if drivers suffer from undue control and intimidation, then police officers suffer from the pressure of making their point. The confident tone of the driver was of no use and in (5) the PO still insisted on his argument and sent the second signal by mentioning the time parameter and the fact that the driver must wait there for a while. This shows the abuse of power on the part of the PO. So entrenched is the inclination to demand money that the driver's tactic has to change from pleading not guilty to accepting the indirect request for bribe. And so, the driver gave back the document accompanied by the indirectly requested money. Thereafter, the PO allowed the truck driver to pass. It can be said that by making some excuses the PO easily succeeded to extort the driver.

\section{DISCUSSION AND CONCLUSION}

CDA is concerned with a thorough analysis of language used in relation to many factors such as power and social inequalities. Specifically, it takes a particular interest in the relationship between language and power. It can assist to construct and reconstruct unequal power relations (Wodak, 2002). In critical discourse analysis, language is not powerful on its own. It gains power by the use that the powerful people make of it. Wodak (2001) also argues that power is signaled not only by grammatical forms within a text, but also by a person's control of a social occasion which by using Halliday's theory of Systemic Functional Linguistics) it is possible to uncover linguistic structures of power in texts. By using CDA, the analysis of conversations in this article revealed the exercise of power by the traffic police officers, while exploiting some sophisticated linguistic techniques to get paid by the drivers. 
It can be stated that the findings of the present study are in line with Van Dijk (2001) proposition that different types of power may be distinguished according to the various resources- language as one of them- employed to exercise such power (p. 355). Different groups such as military forces use language to exercise their coercive power. He adds that the exercise of power is not only limited to the control over what to say (content) but also over how to say (structure). Concerning text and context, members of powerful groups may decide on the (possible) discourse genre(s) or speech acts of an occasion as it was obvious in the analysis of the extracts. The PO's discourse and tone would change the way the drivers would pick their words and the tone of their responses. Also, in agreement with McGregor (2003) in CDA, discourse in the data of this study was analyzed to uncover hidden or implied meanings of the exchanges.

The present study's analysis also shares a common result with Laminu Mele and Bello (2007). They examined the abuse of power of security personnel in Nigeria in their language usage as a mean of extortion. In line with their analysis, this study demonstrates a coercive and threatening discourse adopted by the police officers to be paid money by the drivers. Besides, Van Dijk (2001) states that the military forces would use a kind of language that may confirm or legitimate their abuse of power. For instance, they would repeat the drivers' violation of law on and on and charge them with some extra penalties to make their point to be bribed. This supports the findings of the present study too.

In a nutshell, in the conversations between traffic police officers and drivers, the powerless party (drivers) mostly had to surrender, since the drivers could not afford to waste time and there would be severe consequences for them in case of resistance. In short, while some police officers abuse their power to extort the drivers, the drivers sometime paid bribe in order to avoid a tougher penalty whenever they were guilty. However, these social practices (bribery and extortion) are largely assisted through the use of language, which is exploited and manipulated to suit certain ends. CDA critically unveils these facts.

\section{REFERENCES}

[1] Alexander, J. C., Giesen, B., Munch, R., and Smelser, N. J. (eds). (1987). The Micro-Macro Link. Berkeley, CA: University of California Press.

[2] Anthonissen, C. (2001). On the Effectivity of Media Censorship: An Analysis of Linguistic, Paralinguistic and other Communicative Devices used to defy Media Restrictions. Unpublished PhD thesis. University of Vienna.

[3] Benke, G. (2000). Diskursanalyse als sozialwissenschaftliche Untersuchungsmethode. SWS Rundschau (2), 140-162.

[4] Chouliaraki, L. \& Fairclough, N. (1999). Rethinking Critical Discourse Analysis. Edinburgh: Edinburgh University Press.

[5] Dellinger, B. (1995). Critical Discourse Analysis. Available [accessed 15 jun 2009]: http://brett.-dellinger.tripod.com/

[6] Fairclough, N. (1995). Media Discourse. London: Edward Arnold.

[7] Fairclough, N. L. and Wodak, R. (1997). Critical discourse analysis. In T. A. van Dijk (ed.), Discourse Studies. Multidisciplinary Introduction, vol.2. Discourse as Social Interaction pp. 258-84). London: Sage.

[8] Fowler, R. and B. Hodge. (1979). Critical linguistics. In R. Fowler et al (Eds.). Language and Control. London: Routledge and Keegan Paul. pp. 185-213.

[9] Foucault, M. (1972). The Archaeology of Knowledge. New York: Pantheon.

[10] Fowler, R. (1991). Critical Linguistics. In: Halmkjaer, K. (ed.), The Linguistic Encyclopedia. London/ New York: Routledge. 89-93.

[11] Gramsci, A. (1971). Selections from the Prison Notebooks. London: Lawrence \& Wishart.

[12] Gubrium, Jaber F. and James A. Holstein. (2000). Analyzing Interpretive Practice. In Norman K. Denzin and Yvonna S. Lincoln (eds.), Handbook of Qualitative Research. Thousand Oaks, CA: Sage, 487-508.

[13] Halliday, M.A.K. (1994). Introduction to Functional Grammar. London: Edward Arnold.

[14] Knorr-Cetina, K. and Cicourel, A. V. (1981). Advances in Social Theory and Methodology. Towards an Integration of Microand Macrosociologies. London: Routledge and Kegan PauL.

[15] Kress, G. (1990). Critical Discourse Analysis. Annual Review of Applied Linguistics 11, 84-99.

[16] Laminu Mele, M and Bello, B.M. (2007). Coaxing and coercion in roadblock encounters on Nigerian highways. Discourse \& Society. 18(4), 437-452.

[17] Lukes, S. (1986). Power. Oxford: Blackwell.

[18] McGregor, S.L.T. (2003). Critical Discourse Analysis - A Primer. Critical Science and Critical Discourse Analysis 15(1).

[19] Trew, T. (1979). Theory and ideology at work (pp. 94-116). In: Fowler, R., Hodge, B., kress, G. and Trew, T. (Eds) language and control, Routledge and Kegan Paul, London.

[20] Van Dijk, T.A. (1997). Discourse as Social Interaction. London: Sage.

[21] Van Dijk, T.A. (1998). Opinions and Ideologies in the Press. In Bell, Allan and Peter.

[22] Van Dijk, T. A. (2001). Critical Discourse Analysis. In Tannen, D./ Schiffrin, D./Hamilton, H. (eds.), Handbook of Discourse Analysis. Oxford: Blackwell.

[23] Wodak, R. (2000). Recontextualisation and the transformation of meaning: a critical discourse analysis of decision making in EU-meetings about employment policies. In Sarangi, S./ Coulthard, M. (eds.): Discourse and Social Life. Harlow: Pearson Education, 185-206.

[24] Wodak, R. (2001). The Discourse-Historical Approach. In Wodak, R. and Meyer, M. (Eds.) Methods of CDA. London: Sage.

[25] Wodak, R. (2002). Critical Discourse Analysis. In Schiffrin, D. (ed.) Handbook in Discourse Analysis. Oxford, Blackwells.

[26] Wrong, D. H. (1979). Power: Its Forms, Bases and Uses. Oxford: Blackwell. 


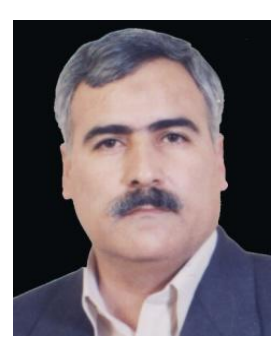

Hossein Vahid Dastjerdi (b. 1955, Isfahan, Iran) teaches in the English Language Department at the University of Isfahan, Iran. He is associate professor of applied linguistics and has taught courses of variegated character, including translation courses, for years. He has been a fellow of the English Centers at the universities of Isfahan and Shiraz where he has investigated into issues related to materials preparation for GE. and ESP. courses. He is the author of a number of books in this respect. He has also published a good number of articles on discourse, testing and translation in local and international journals.

Dr. Vahid's current research interests include testing, materials development, translation, the metaphoricity of language, discourse analysis, pragmatics and critical discourse analysis. He is presently involved in a number of projects concerning translation studies as well as figurative language use.

Mehdi Latifi (b. 1983, Isfahan, Iran) is currently a Ph. D. candidate at the University of Isfahan, Isfahan, Iran. He received his M.A. in TEFL from the University of Isfahan. His area of interest is listening comprehension.

Elham Mohammadi (b. 1985, Isfahan, Iran) is currently an MA student at the University of Isfahan. Her area of interest is Taskbased language teaching. 